\title{
Vulnerability of Road Pavements to Climate Change in Abia and Imo States of Nigeria
}

\author{
A. O. Ibeje* \\ Department of Civil Engineering, Imo State University, Owerri, Imo State, NIGERIA.
}

\begin{abstract}
Around the world today, road pavement is increasingly vulnerable and Southeast Nigeria is no exception. To this end, the Delphi technique is used in this study to ascertain experts opinions in order to identify and prioritize road pavements vulnerable to climate change in Abia and Imo states of Southeast Nigeria. As a measure of stability, standard deviation of two rounds of questionnaire responses was used to assess the level of convergence of opinions of 10-member Delphi panel. The Delphi panel achieved acceptable level of agreement at threshold values of standard deviation $=0.10$ for stability and mean $=0.20$ for consensus. Out of 14 federal roads considered in the study, 1 road had high vulnerability status, 5 roads had medium vulnerability status, 5 roads were rated low vulnerability and 2 roads were rated very low vulnerability. The only highly vulnerable road is from Abia state. This study has shown that the vulnerability of road pavements to climate change can be assessed comprehensively using collective and subjective judgement in the form of Delphi technique. Government should therefore apply adaptive maintenance plans that reflect the relative vulnerability rating of these roads.
\end{abstract}

Keywords: climate change, Delphi technique, road pavements, vulnerability

\section{INTRODUCTION}

Design engineers rely on long historical records of climatic data when designing road infrastructures [1]. With this conventional practice, roads can withstand local weather and climate [2]. Unfortunately, climate change has distorted trend in climate, thus this renders the use of historical climate data in the design of road infrastructure unreliable.

Road administrators worldwide are concerned about the change in climate during the past decades because of increasingly significant impacts on road infrastructure. Some evidence of impacts of climate change on road infrastructure include: excessive solar radiation that damages road surface, uncommon and frequent submergence of road by severe flood events, increased coverage of roads with snow and ice etc [3]. Local communities and businesses are also affected by the damage of road pavements due to climate change [4]. When roads are washed away by floods, movement of people, goods and services around a region are restricted thus, impacting upon local economy, environment, the health and wellbeing of residents [5]. From social point of view adverse weather events can isolate communities from medical care, denial of assess to employment and normal daily activities [6]. High-

\footnotetext{
${ }^{*}$ Corresponding author (Tel: +2438039381505$)$ Ibeje)
}

way networks receive heavy traffic with grave consequences as people migrate due to severe climate [7]. [8] observed that climate was already having influence on Nigerian roads, although the impacts are non-uniformly experienced across the country. In northern Nigeria, impact of climate change on road pavement is derived from high harmattan temperature whereas in the south, road infrastructure is heavily impacted by extreme rainfall events [9]. The severity of climate impacts is exacerbated by soil type, topographical features, type and previous pavement conditions.

Vulnerability generally refers to the likelihood of injury, death, loss, disruption of livelihood or other harm, manifested in the form of risks, as a result of environmental shocks or harm resulting from social changes [10]. Vulnerability to climate change is the degree to which a system is susceptible to, or unable to cope with, adverse effects of climatic change, including climate variables and extremes. [1] explores vulnerability through three core concepts: firstly, exposure magnitude to which a system is physically in harm's way; secondly, the sensitivity of a system i.e., its likelihood to be affected by a shock; and thirdly, the adaptive capacity of a system to cope or adjust with the negative impacts of a shock $[6,11,12]$. Regardless of location, the vulnerability of road pavement depends on its robustness and degree of protection from exposure to changes in temperature, precipitation, sea level, and extreme weather events [13].

In the South East Nigeria, climate change has caused excessive flooding leading to gully erosion 
development. This has led to the destruction of homes, inundating of farmlands, thus leading to poverty among the local population. By adding climate change factor, the competition between water demands (e.g. urban development, agriculture, hydropower, industry) have even become more severe in the South Eastern Nigeria. A review of historical climate trends for Southeastern States of Nigeria suggests that the trend of rainfall was decreasing for all the states in southeast Nigeria with the lowest trend rate of $-0.1153 \mathrm{~mm}$ rainfall occurring in Umuahia, Abia state [14]. In the case of air temperature, it was observed that the trend is increasing for all the study areas in Southeast with the highest trend rate of $0.04698^{\circ} \mathrm{C} /$ year occurring in Enugu [14]. In the 2016 publication of the Federal Ministry of Information and Culture, in southern Nigeria, climate change is reflected in the massive flood experienced in 2012. Houses, farms, farm products and even human beings were swept away. Rising sea levels are threatening Nigeria coastal regions. This change in climate also makes roads in Southeast Nigeria to be vulnerable to climate change.

\subsection{The Delphi Technique}

The Delphi method is a structured process for collecting and distilling knowledge from a group of experts using a series of questionnaires with controlled opinion feedback [8]. Delphi Technique involves assembling groups of experts without concern for geography, and who then reply to a number of rounds of questioning through email [15]. [16] reports that Delphi technique has been used in areas like planning, environmental impact assessment etc. The use of Delphi techniques in the determination of road vulnerability is new. By identifying vulnerability of roads to climate change, future changes in climate would be acknowledged and mitigation measures adopted. Outcomes of vulnerability assessment are useful in furnishing road facilities that are resilient to climate variability and extreme weather events. There is grave need to ascertain the vulnerability of road pavements in selected areas of Nigeria. This study is aimed at investigating the vulnerability of road pavements to climate change in Abia and Imo states, southeast of Nigeria using Delphi technique.

\section{METHODOLOGY}

\subsection{Study Area}

Abia and Imo states of southeast Nigeria are the study areas of this study. [17] asserted that Abia and Imo states, are located between latitude $40^{\circ} 41^{\prime}$ and $80^{\circ} 15^{\prime} \mathrm{N}$ and longitude $6^{\circ} 40$ and $8^{\circ} 15^{\prime} \mathrm{E}$ respectively. In Abia and Imo states, the major geological formations include Alluvium, Coastal plain sands (Benin formation), Shale (Bende Ameki formation), Lower coal measures (Mamu formation), Upper coal measures (Nsukka formation) and False-bedded sandstone [18]. [19] reported that plains and lowlands abound in these areas. In Abia and Imo states, wet season lasts for 9 months because of humid climate. Farming forms the major socio-economic activity of these areas as they are dominated by forestlands [20]. The study areas are presented in Fig. 1.

\subsection{Data Collection and Analysis}

\subsubsection{Constitution of Delphi panel and question- naires}

The flowchart of the steps involved in Delphi technique is presented in Fig. 2. Initially, panelists were selected from only experts who are based in Nigeria in order to reduce variability due to alien political and organizational environments of non-Nigerian residents, which differ with that Nigeria. Panel members, who were working in or had worked in road pavement management, were selected from the following: (1) government, (2) private companies, (3) research centers, and (4) university institutions. The age distribution of the respondents ranged from 20 to 60 years, with a majority $84 \%$ falling between 30 and 49 year. In addition, $92 \%$ of the respondents acquired postgraduate degrees.

\subsubsection{Implementation of Delphi technique}

A number of 'rounds' of question(s) were sent to the Delphi panel through email. Points of agreement in the response to each round of questions were sent as feedback to the participants. The rounds of questioning continued until the responses became consistent among the participants. These responses of the participants were hidden from one another to avoid undue influence over opinions one another. When consensus was achieved, the number of rounds of questions was stopped [15]. This is the goal of Delphi technique; to achieve stability in group and individual responses such that they do not vary from round to round.

\subsubsection{Statistical analysis for stability and consen- sus}

The measure of change in the response of Delphi panelists to different rounds of questioning is called stability. Stability is often used as a tool to decide on whether a Delphi process is discontinued. Standard deviation was used to detect change in variation of responses in different rounds of questioning. In this study, value of 0.10 for the standard deviation of responses to questions was set as the threshold of stability after two rounds of questioning. This was adopted from the approach used by [15, 21]. The agreement among Delphi experts is called consensus [21]. In this study, mean of responses was adopted as a measure of consensus and 0.20 was adopted as the threshold of consensus [21].

\subsubsection{Assessing exposure of road pavement to cli- mate change}

In order to estimate roads exposure to climate change, the roads and their locations were initially identified. To demonstrate the rating scale for estimating exposure, the scoring matrix in Table 1 was adopted. Dephi experts selected climate 


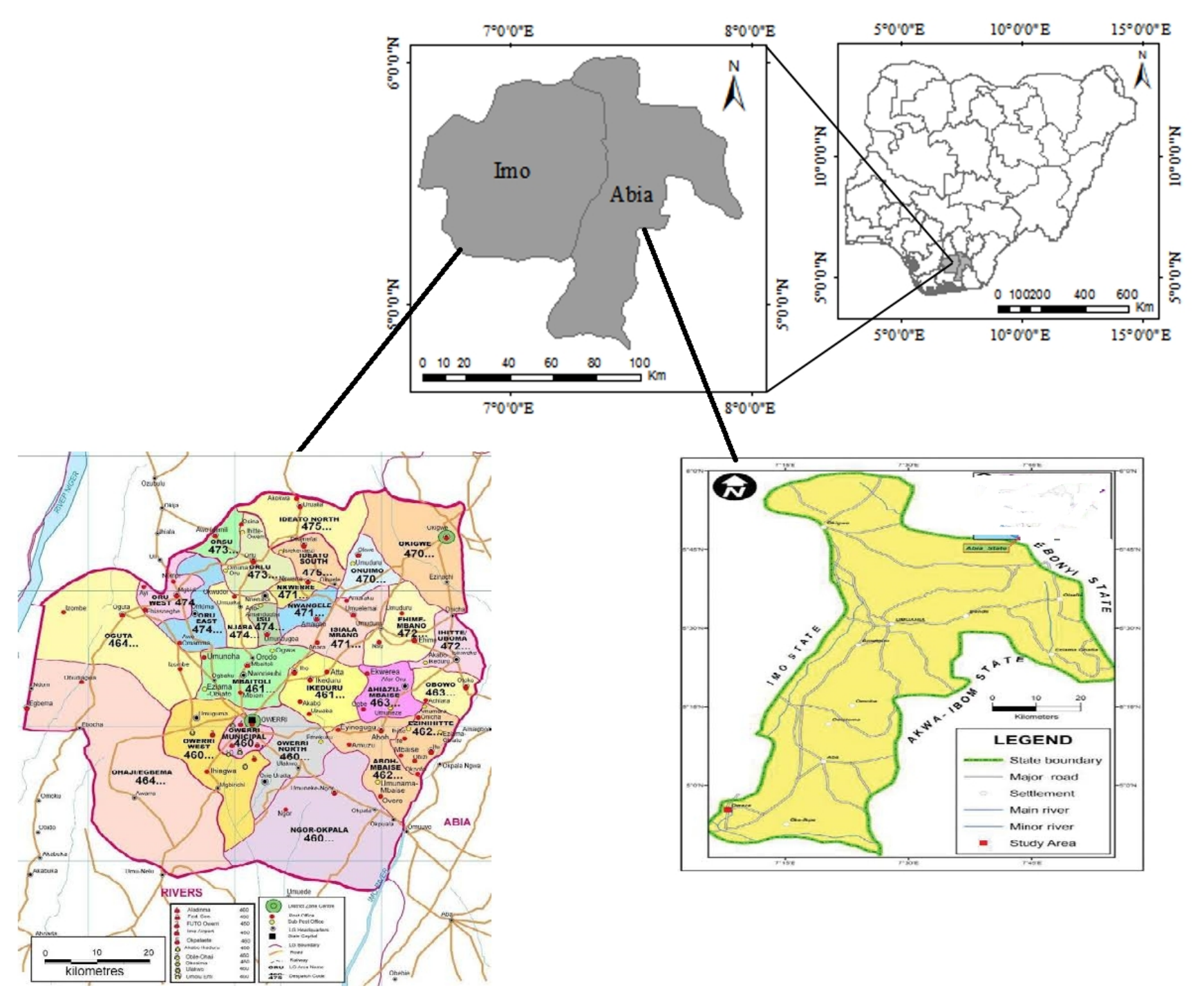

Figure 1: Location Map of the Study Areas 


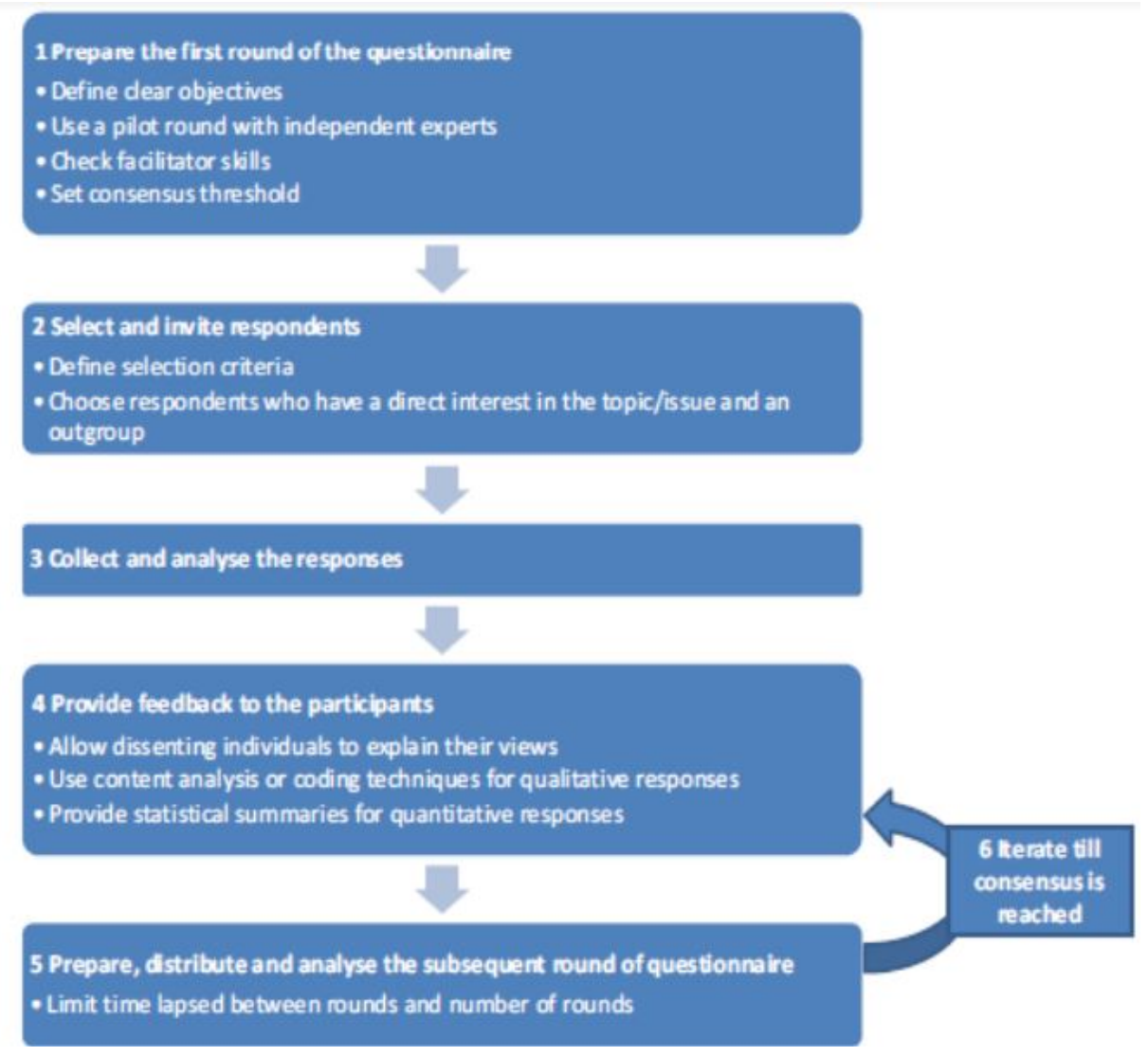

Figure 2: Flowchart of the steps involved in Delphi technique

variables appropriate to the location based on historical experience and events.

\subsubsection{Assessing sensitivity of road pavement to climate change}

Sensitivity was assessed using: experience of recent and historical events; geographical location and asset condition and design life. Furthermore, if an asset was nearing the end of its design life it may be more sensitive to climatic impacts. The Delphi panel produced a consensus table for assigning rating scale for sensitivity as presented in Table 2. Table 2 was used as example scale to assign high, medium and low sensitivity.

\subsubsection{Calculation of vulnerability levels}

Through combining the exposure and sensitivity ratings, it was possible to identify whether the asset was vulnerable, to what degree, and to which climate variables. Assets having high exposure and sensitivity were assigned a higher vulnerability to the climate variable than those with a low exposure and low sensitivity. Those with low vulnerability to the climate variables were less likely to require adaptation strategies to be put in place to protect them. The vulnerability matrix shown in Table 3 shows how exposure and sensitivity was used to determine overall vulnerability level.

Low Vulnerability implied that the asset was less vulnerable, adaptation and/or mitigation would be beneficial. Very Low Vulnerability implied that the asset was not vulnerable, adaptation and/or is very unlikely to be necessary.

\section{RESULTS AND DISCUSSION}

\subsection{Survey Results for Road Exposure to Cli- mate Change}

In survey round 1 (SR1), in Abia State, AbaObigu Road was the most exposed with an average rating of 1.5 with highest rating of 3 by groups 3 and 4 participants and lowest rating of 0 by groups 1 and 5 Survey participants (SPs). Okpala - Ngwa - Aba Road scored an average 1.2 and was the least exposed. Its highest rating was 3 , and its lowest rating was 0 . This road was rated high by groups 3 and 4 SPs. In Survey round 2 (SR2), the average, lowest, highest, and overall rating of each road was obtained and provided to SPs from SR1. Aba - Obigu and Okpala - Ngwa - Aba Roads scored an average of 1.5 and were rated the most exposed with highest rating of 3. Umuahia - Okpala - Ngwa Road was rated lowest and was the least exposed.

In Imo State, SR1, Aboh-Olakwo Road was the most exposed with an average rating of 2 with highest rating of 3 by groups 3,4 and 5 SPs and lowest rating of 0 by group 1 SPs. Olakwo - Okpala Road scored an average 1.1 and was the least exposed. Its highest rating was 3, and its lowest rating was 0 . This road was rated high by group 4 SPs. In the results of SR2, Aboh - Olakwo Road 
Table 1: Rating scales for assessing exposure.

\begin{tabular}{l|c|c|c|c|c|c}
\hline & $\begin{array}{c}\text { Extreme } \\
\text { Heat }\end{array}$ & $\begin{array}{c}\text { Mean } \\
\text { Heat }\end{array}$ & Drought & $\begin{array}{c}\text { Mean } \\
\text { Rainfall }\end{array}$ & $\begin{array}{c}\text { Storms/ Extreme } \\
\text { Rainfall }\end{array}$ & $\begin{array}{c}\text { Sea Level Rise } \\
\text { and/or Storm Surge }\end{array}$ \\
\hline Asset/Location/ Operation A & & & & & & \\
\hline Asset/ Location/ Operation B & & & & & & \\
\hline Asset/ Location/ Operation C & & & & & & \\
\hline Asset/Location/Operation D & & & & & & \\
\hline
\end{tabular}

Exposure can be scored as follows: $0=$ No or negligible exposure now and/or in the future; $1=$ Low exposure now and/or in the future; $2=$ Medium exposure now and/or in the future; $3=$ High exposure now and/or in the future.

Table 2: Rating scales for accessing sensitivity

\begin{tabular}{|c|c|}
\hline Level of sensitivity & Description o sensitivity level to infrastructure \\
\hline 3 High & Permanent or extensive damage requiring extensive repair \\
\hline 2 Medium & $\begin{array}{l}\text { Widespread infrastructure damage and service disruption requiring moderate repairs. } \\
\text { Partial damage to local infrastructure. }\end{array}$ \\
\hline 1 Low & $\begin{array}{l}\text { Localized infrastructure service disruption. No permanent damage. Some minor } \\
\text { restoration work required. }\end{array}$ \\
\hline 0 Negligible & No infrastructure service disruption or damage. \\
\hline
\end{tabular}

scored an average of 2 and was rated the most exposed with highest rating of 3 . Okigwe - muahia Road was rated 1.1 and was the least exposed.

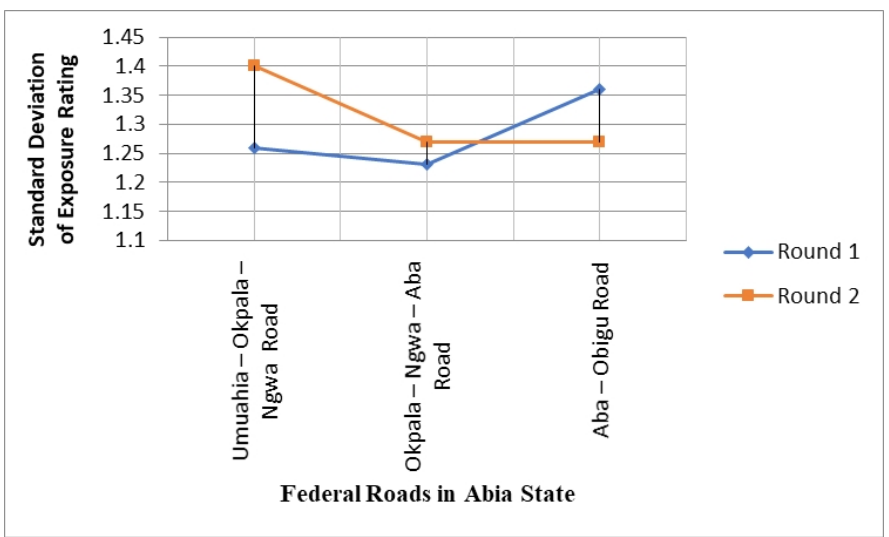

Figure 3: Standard deviation of exposure rating of federal roads in Abia State

\subsection{Convergence of Responses in Exposure Survey}

In Abia State, standard deviations of responses for each road were compared SR1 and SR2 as shown in Fig. 3.

The standard deviation of the exposure ratings of all the roads studied increased from SR1 to SR2.This was because some SPs decreased their rating of the roads while other SPs kept their rating the same. Standard deviations of group responses for each road ranged between $1.23-1.40$.

In Imo State, standard deviations of responses for each road were compared on SR1 and SR2 as shown in Fig. 4.

For Aboh - Awarra, Awarra - Umunelo and Owerri - Obaku roads, the standard deviations of the ratings remained the same at $1.43,1.35$ and 1.35 respectively, from SR1 to SR2. This indicated that the panel members' ratings were agree-
Table 3: Vulnerability matrix.

\begin{tabular}{lccc}
\hline & \multicolumn{3}{c}{ Sensitivity } \\
\cline { 2 - 4 } Exposure & Low & Medium & High \\
High & 4(Medium) & 5(High) & 6(Extreme) \\
Medium & 3(Low) & 4(Medium) & 5(High) \\
Low & 2(Very Low) & 3(Low) & 4(Medium) \\
\hline
\end{tabular}

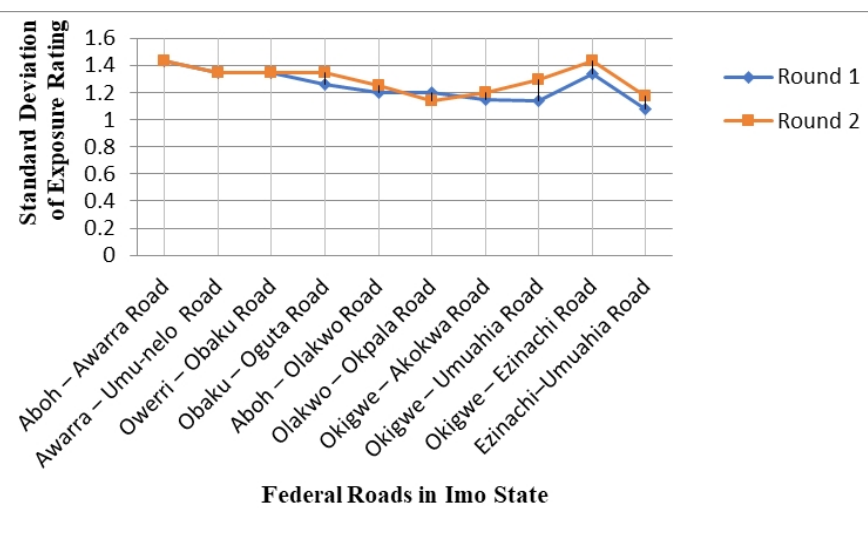

Figure 4: Standard deviation of exposure rating of federal roads in Imo State.

ing. However, the standard deviations of the responses for the rest of the roads increased from SR1 to SR2. This showed some level of disagreement among the panel members' ratings. For all the roads studied in Imo state, the standard deviations of group responses for road exposure to climate change ranged between the range from 0 -1.43 .

\subsection{Road Sensitivity to Climate Change}

In Abia State, the average, lowest, and highest sensitivity rating for each road in SR 1 was tabulated and presented to the SPs with instructions for SR2. Okpala-Ngwa-Aba Road was the most sensitive with an average rating of 2.15 with high- 
est rating of 3 . Aba - Obigu Road scored an average 1.38 and was the least sensitive. In Imo State, SR 1, Okigwe - Umuahia Road was the most sensitive with an average rating of 3 . Owerri - Obaku Road scored an average 0.38 and was the least sensitive. The results of SR2, Okigwe - Umuahia Road scored an average of 2.88 and was rated the most sensitive. Owerri - Obaku Road was rated 0.5 and was the least sensitive.

\subsection{Convergence of Responses in Sensitivity Survey}

In Abia State, standard deviations of responses for each road were compared on SR1 and SR2 as shown in Fig. 5.

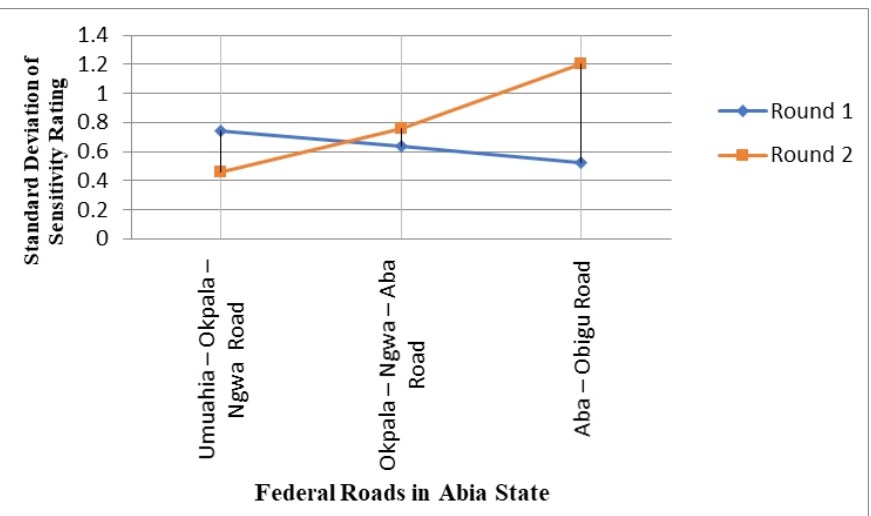

Figure 5: Standard deviation of sensitivity rating of federal roads in Abia State.

Unlike the exposure rating, a road in Abia state had decreased standard deviation from SR1 to SR2 in the sensitivity rating, namely: Umuahia Okpala - Ngwa Road. The sensitivity rating of the road converged with standard deviations of 0.46 . The standard deviation of the ratings of the other roads studied increased from round 1 to round 2 . For all the roads studied in Abia state, the standard deviations of group responses for road sensitivity to climate change ranged between the range from $0.46-1.20$.

In Imo State, standard deviations of responses for each road were compared on SR1and SR2 as shown in Fig. 6. For Aboh - Awarra, Awarra Umunelo and Okigwe - Akokwa roads, the standard deviations of the ratings remained the same at $0.46,0.83$ and 0.71 respectively, from SR 1 to SR2.

This indicated that the panel members' ratings were agreeing. The standard deviation of sensitivity ratings for Obaku - Oguta, Olakwo - Okpala and Ezinachi - Umuahia roads decreased from SR1 to SR2 as $0.71,0.83$ and 0.89 respectively. However, the standard deviations of the responses for the rest of the roads increased from SR1 to SR2. For all the roads studied in Imo state, the standard deviations of group responses for road exposure to climate change ranged between the range from $0-1.31$.

\subsection{Road Vulnerability to Climate Change}

In Abia State, SR1, the result of vulnerability survey is shown in Table 4. Aba - Obigu Road was the most vulnerable with a medium rating of 4 with medium exposure rating of 2 and medium sensitivity rating of 2 . Umuahia - Okpala - Ngwa Road scored a low rating of 3 and was the least vulnerable on the vulnerability scale. Its exposure rating was 2 , and its sensitivity rating was 1. For SR2, Aba-Obigu Road was the most vulnerable with a high rating of 5 with medium exposure rating of 2 and high sensitivity rating of 3 . Umuahia - Okpala - Ngwa Road scored 2 and was the least vulnerable on the vulnerability scale. Its exposure rating was 1 , and its sensitivity rating was 1.

For average and overall ratings, Aba - Obigu road scored an average of 4.5 and was rated the most vulnerable with highest rating of 5 while Umuahia - Okpala - Ngwa road was rated 2 and was the least vulnerable road. In Imo State, SR1, the result of vulnerability survey is shown in Table 4. For average and overall ratings, Aboh Olakwo, Okigwe - Akokwa, Okigwe - Umuahia and Ezinachi-Umuahia Roads scored an average of 4 and were rated the most vulnerable. Awarra - Umunelo Road was rated 2 and was the least vulnerable road.

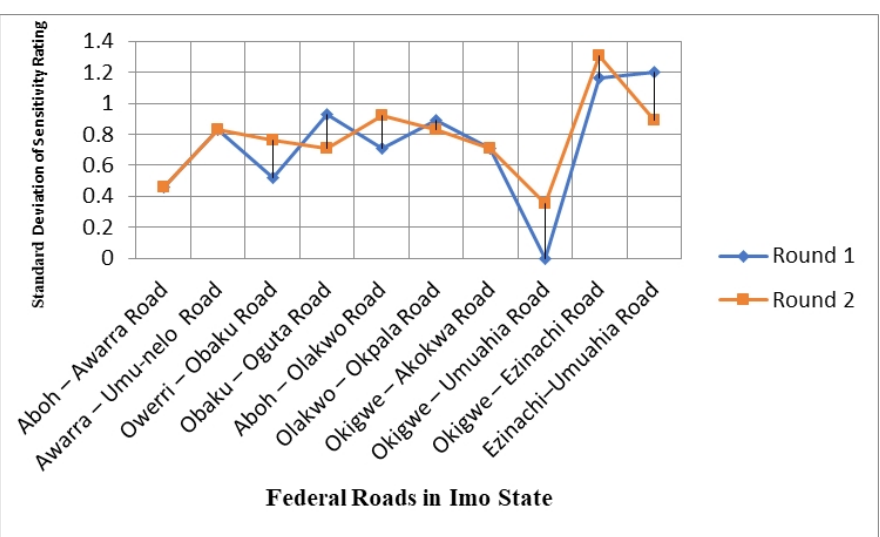

Figure 6: Standard deviation of sensitivity rating of federal roads in Imo State.

Table 4 shows the summary of Delphi survey results. Out of 14 federal roads considered in the study, 1 road had high vulnerability status, 5 roads had medium vulnerability status, 5 roads were rated low vulnerability and 2 roads were rated very low vulnerability.

This represented $7 \%$ highly vulnerable, $36 \%$ medium vulnerable, $36 \%$ low vulnerability and $14 \%$ very low vulnerability of federal roads to climate change in Abia and Imo States of south eastern Nigeria. The only highly vulnerable road is in Abia state. Out of the 5 medium vulnerable roads, 4 are in Imo state. For the 2 roads of very low vulnerability status, 1 is in Abia and 1 is in Imo.

\section{CONCLUSION}

In order to understand the vulnerability of road pavement to climate change, key indicators of sensitivity and exposure of 14 federal roads in Abia 
Table 4: Summary of Delphi survey results.

\begin{tabular}{llcl}
\hline State & Road section & $\begin{array}{c}\text { Vulnera- } \\
\text { bility rate }\end{array}$ & $\begin{array}{l}\text { Vulnera- } \\
\text { bility }\end{array}$ \\
\hline Abia & Aba - Obigu & 5 & High \\
Abia & Okpala - Ngwa - Aba & 4 & Medium \\
Imo & Ohali - Awgu & 4 & Medium \\
Imo & Obodo - Ngwo & 4 & Medium \\
Imo & Ohali - Awgu & 4 & Medium \\
Imo & Obodo - Ngwo & 4 & Medium \\
Imo & Aboh - Awarra & 3 & low \\
Imo & Owerri - Obaku & 3 & low \\
Imo & Obaku - Oguta & 3 & low \\
Imo & Olakwo - Okpala & 3 & low \\
Imo & Okigwe - Ezinachi & 3 & low \\
Abia & Umuahia - Okpala - & & \\
& Ngwa & 2 & Very low \\
Imo & Awarra - Umunelo & 2 & Very low \\
\hline
\end{tabular}

and Imo states of Nigeria were explored through repetitive rounds of questioning called Delphi technique. There were stability and consensus in the responses of the participants after two rounds of questioning. Non-climatic factors such as land use, governance and policy groups were also observed to increase the exposure of these federal roads to climate change. In the study, it was observed that the vulnerability of a federal road in Abia state to climate change was quite high. There is need for greater awareness, information and dialogues for better understanding of climaterelated risks/opportunities among stakeholders. It is recommended that more community-based case studies involving a wider range of stakeholders is required to understand the dynamics of road vulnerability to aid proper policy formulation.

\section{References}

[1] C. R. Bennett, A. Chamorro, C. Chen, H. De Solminihac, and G. Flintsch. Data collection technologies for road management. Report to the World Bank. [Online]. Available: www.lpcb.org

[2] J. J.M., P. Kirshen, and J. Daniel, "Considering climate change in road and building design," EOS Earth and Planetary Sciences, vol. 94, p. 264, 2013.

[3] IPCC, "Climate Change 2014: Impacts, Adaptation, and Vulnerability. Part A: Global and Sectoral Aspects." Cambridge University Press, 2014.

[4] J. Barnett and S. O’Neill, "Maladaptation," Global Environmental Change, vol. 20, no. 2, pp. 211-213, 2010

[5] E. Barrow, B. Maxwell, and P. Gachon, "Climate Variability and Change in Canada: Past, Present and Future, ACSD Science Assessment." Meteorological Service of Canada, Environment Canada, Toronto, Ontario, p. 114, 2004.

[6] T. C. Peterson, M. Marjorie, G. H. Tamara, H. H. Andrew, and W. Michael, "Climate variability and change with implications for transport," 2006.

[7] D. Reckien, K. E., and H. Esther, Adaption to climate change in the transport sector: the constraining effect of actor-interdependencies. Potsdam, Germany: Potsdam Institute for Climate Impact Research, 2009.

[8] W. N. Adger, "Vulnerability," Global Environmental Change, vol. 16, pp. 268-281, 2006.

[9] J. Akinbami and S. Fadare, "Strategies for sustainable urban and transport development in Nigeria," Transport Policy, vol. 4, no. 4, pp. 237-245, 1997.

[10] K. O'Brien, S. Eriksen, L. Nygaard, and A. Schjolden, "Why different interpretations of vulnerability matter in climate change discourses," Climate Policy, vol. 7, pp. $73-88,2007$.
[11] J. J. McCarthy, Climate Change 2001: Impacts, Adaptation, and Vulnerability. Cambridge University Press, 2001.

[12] B. Smit and O. Pilifosova, "Adaptation to climate change in the context of sustainable development and equity," Sustain. Dev., vol. 8, no. 9, p. 9, 2003.

[13] Transportation Research Board, "Potential impacts of climate change on U.S. transportation," 2008, transportation Research Board Special Report 290.

[14] B. N. Ekwueme, "Analysis and prediction of the effect of climate change on flood in southeastern Nigeria," Unpublished, Faculty of Engineering, University of Nigeria, Nsukka, 2020.

[15] H. A. Linstone. (2002) The delphi method: Techniques and applications. [Online]. Available: http://is.njit.edu/ pubs/delphibook/delphibook.pdf

[16] H. Sackman, Delphi critique, M. Lanham, Ed. Lexington Books, 1975.

[17] FDAR, "The reconnaissance soil survey of Imo State, Nigeria (1:250,000)," Tech. Rep., 1985, Soils Report.

[18] S. O. Orajaka, "Geology," in Nigeria in maps: Eastern States, G. E. K. Ofomata, Ed. Benin City: Ethiope Publishing House, 1975, pp. 5-7.

[19] G. E. K. Ofomata, "Landform regions," in Nigeria in maps: Eastern States, G. E. K. Ofomata, Ed. Benin City: Ethiope Publishing House, 1975, pp. 33-34.

[20] M. U. Igbozuruike, "Vegetation types," in Nigeria in maps: Eastern States, G. E. K. Ofomata, Ed. Benin City: Ethiope Publishing House, 1975, pp. 30-32.

[21] H. Von der Gracht, "The delphi technique for futures research," in The Future of Logistics: Scenarios for 2025 H. Von der Gracht, Ed. Cambridge University Press, 2008, pp. 21-68. 